\title{
OUALIDADE TOTAL: UMA NOVA ERA PARA OS SUPERMERCADOS
}

Francisco José Grandis Rojo Professor do Departamento de Mercadologia da EAESP/FGV.

RESUMO: O autor apresenta um estudo, baseado em sua tese de doutorado, sobre a busca de qualidade total nos supermercados. Analisa um cenário de crescente competitividade, no qual os consumidores estão cada vez mais exigentes, induzindo os dirigentes de supermercados a buscar mais qualidade, eficiência e produtividade em suas operações.

ABSTRACT: The author presents a study, based on his Ph.D. thesis, about total quality management at supermarkets. He analyzes a scenery of growing competitiveness, where consumers are more demanding, inducing supermarkets managers to search for more quality, efficiency and productivity.

PALAVRAS-CHAVE: supermercados, qualidade total, eficiência, produtividade, satisfação dos consumidores.

KEY WORDS: supermarkets, total quality management, eficiency, productivity, consumers' satisfaction. 
O setor de supermercados movimenta cerca de $\mathrm{R} \$ 50$ bilhões anuais e a partir da estabilização econômica vem passando por transformações em busca de qualidade, eficiência e produtividade.

\section{A EVOLUÇÃO DOS SUPERMERCADOS NO BRASIL}

Os dados de Nielsen ${ }^{1}$ mostram que, a partir da década de 70, houve um expressivo crescimento da participação dos supermercados na distribuição de alimentos no Brasil. No início dos anos 70, os supermercados representavam $26 \%$ das vendas de gêneros alimentícios no mercado brasileiro. Desde então, passaram a se desenvolver, chegando a alcançar uma participação de $85 \%$, conforme mostra a Figura 1. elevados, advindos do rápido giro de estoques em relação a prazos de pagamento aos fornecedores. A remarcação de preços contribuía para a viabilização dos resultados, ajudando a encobrir eventuais ineficiências na operação das lojas. A estabilidade econômica e os baixos índices de inflação alcançados a partir do Plano Real, em julho de 1994, mudaram ainda mais algumas características do setor.

Com a estabilização da economia e o aumento da competitividade, os supermercados foram impelidos a buscar maior eficiência na administração do negócio. Essa mudança no setor já era prevista no início do Plano Real pelo então Presidente da ABRAS - Associação Brasileira de Supermercados -, Levy Nogueira, ao ressaltar que "numa situação econômica estável, com

Figura 1 - A participação dos supermercados na distribuição de alimentos no Brasil (1970 a 1996)

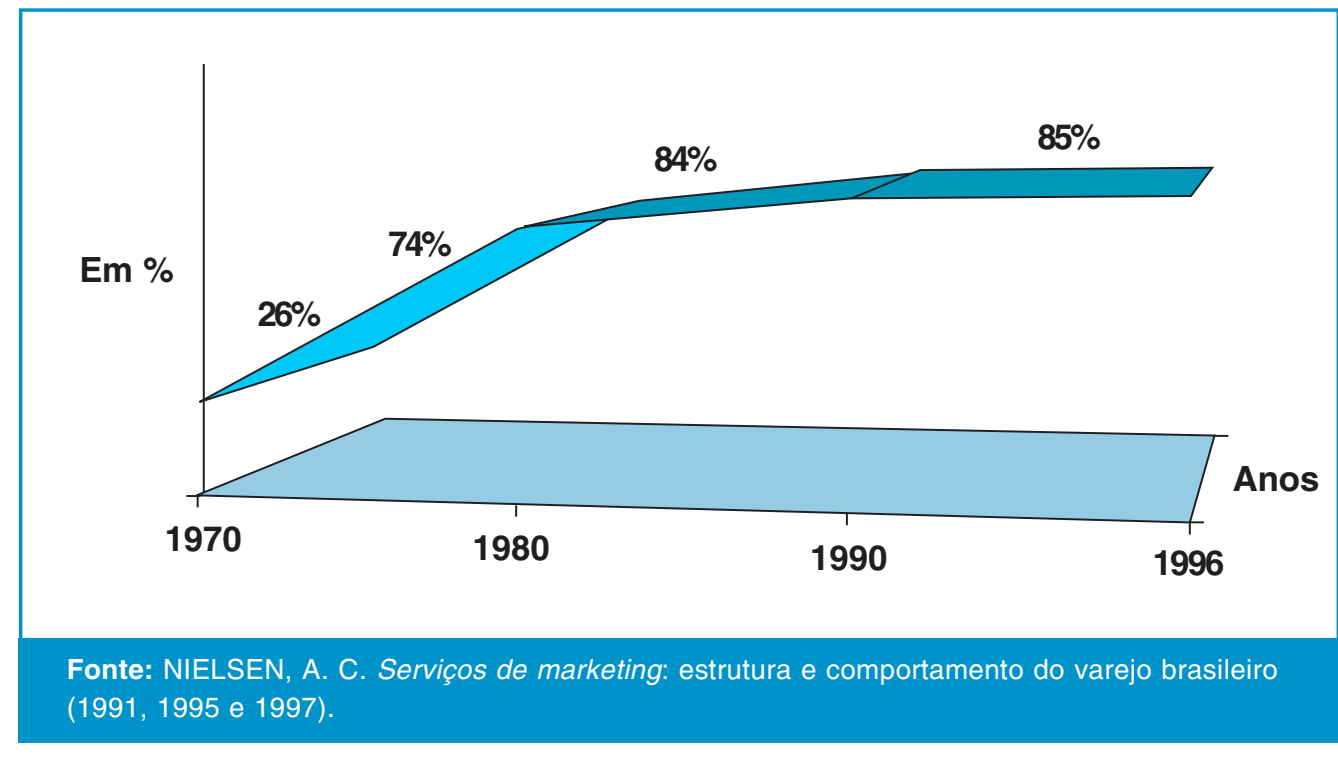

Conforme demonstra relatório da ABRAS, ${ }^{2}$ a evolução dos supermercados imprimiu um forte ritmo de desenvolvimento ao setor e, particularmente nos últimos anos, a competitividade entre as lojas tem sido crescente. A maior competitividade vem exigindo caminhos criativos e eficientes para a sobrevivência e a diferenciação no negócio.

\section{A estabilização econômica provocou mudanças no setor supermercadista}

Durante o período inflacionário, muitos varejistas obtinham ganhos financeiros mais preços relativos alinhados, sem as enormes diferenças ditadas pelo descontrole inflacionário, é preciso, antes de mais nada, controlar os custos do negócio. Quanto menor for o gasto da operação, maior será a capacidade de competição, a garantia de lucratividade. Uma questão fundamental é que a busca de redução de custos e maior eficiência não pode arranhar a qualidade da operação, desde o sortimento até o relacionamento com o público". ${ }^{3}$ Assim, de maneira até previsível, os supermercados passaram a enfrentar uma nova realidade na gestão de seus negócios a partir do Plano Real.
1. NIELSEN, A. C. Estrutura do varejo brasileiro. São Paulo, 1997.

2. ABRAS - Associação Brasileira de Supermercados. 40 anos de supermercados no Brasil. São Paulo, 1993. p.1-56.

3. NOGUEIRA, Levy. Ranking: um espelho do setor. Superhiper, jun. 1994, p.3. 
4. AGAS - Associação Gaúcha de Supermercados. Brava gente brasileira. Porto Alegre, ago. 1996, p.12-22.

5. FEIJÓ, Paulo A. Palavra do Presidente. Superhiper, maio 1996, p.3.

6. DEMING, W. Edwards. Qualidade: a revolução da administração. Rio de Janeiro: Marques Saraiva, 1990. p.12435 .

7. SCHOLTES, Peter R. Times da qualidade: como usar equipes para melhorar a qualidade. Rio de Janeiro: Qualitymark, 1992. p.8-9.

8. BUZZELL, Robert D., GALE, Bradley T. PIMS (Profit Impact of Market Strategy). o impacto das estratégias de mercado no resultado das empresas. São Paulo: Pioneira, 1991. p.131-70.
Uma análise do setor desenvolvida pela AGAS - Associação Gaúcha de Supermer$\operatorname{cados}^{4}$ - reforça a percepção de que após a estabilização da economia ocorreu um acirramento da concorrência, o volume de vendas cresceu, enquanto as margens de lucro foram pressionadas para baixo, levando as empresas a perseguir vantagens competitivas por meio de serviços melhores e da busca incessante da eficiência administrativa. Segundo a AGAS, o segmento supermercadista está sendo obrigado a repensar seu negócio, com muitos ajustes em busca de um novo modelo de operação baseado no controle mais eficiente dos negócios e na satisfação do clientes.

Para Feijó, ${ }^{5}$ atual Presidente da ABRAS, quem desejar continuar no mercado terá de assimilar as mudanças de comportamento e atender às crescentes exigências dos consumidores. Consideramos que, diante desse cenário, os conceitos de qualidade total surgem como uma relevante contribuição para o aprimoramento da operação nos supermercados.

\section{A QUALIDADE TOTAL COMO CAMINHO PARA EFICIÊNCIA E PRODUTIVIDADE}

Segundo Deming, ${ }^{6}$ o caminho para o desenvolvimento das empresas é a liderança em qualidade. Deming enfatiza os resultados, trabalhando nos métodos, dando prioridade máxima às preocupações do cliente para estudar e melhorar constantemente todos os processos de trabalho, de modo que o produto ou serviço final exceda as expectativas do cliente, à medida que a empresa alcança melhores resultados.

O modelo de reação em cadeia de Deming (Figura 2) mostra as etapas pelas quais o processo de busca de qualidade proporciona o desenvolvimento da empresa.

Conforme mostra Scholtes, ${ }^{7}$ Deming reforça a importância de dar prioridade máxima às preocupações do cliente, visando a estudar e melhorar constantemente todos os métodos e processos de trabalho. A empresa deve fazer com que o produto ou serviço final exceda as expectativas do cliente.

A percepção de maior retorno sobre o investimento a partir da melhoria da qualidade, mostrada no modelo de reação em cadeia de Deming, é reforçada por Buzzell \& Gale $^{8}$ no Projeto PIMS - Profit Impact of Market Strategy. Não há dúvidas de que a qualidade superior, percebida pelo cliente, e a rentabilidade estão fortemente relacionadas.

A Figura 3 mostra a relação positiva entre qualidade percebida, retorno sobre vendas e retorno sobre investimento.

Figura 2 - Modelo de reação em cadeia de Deming

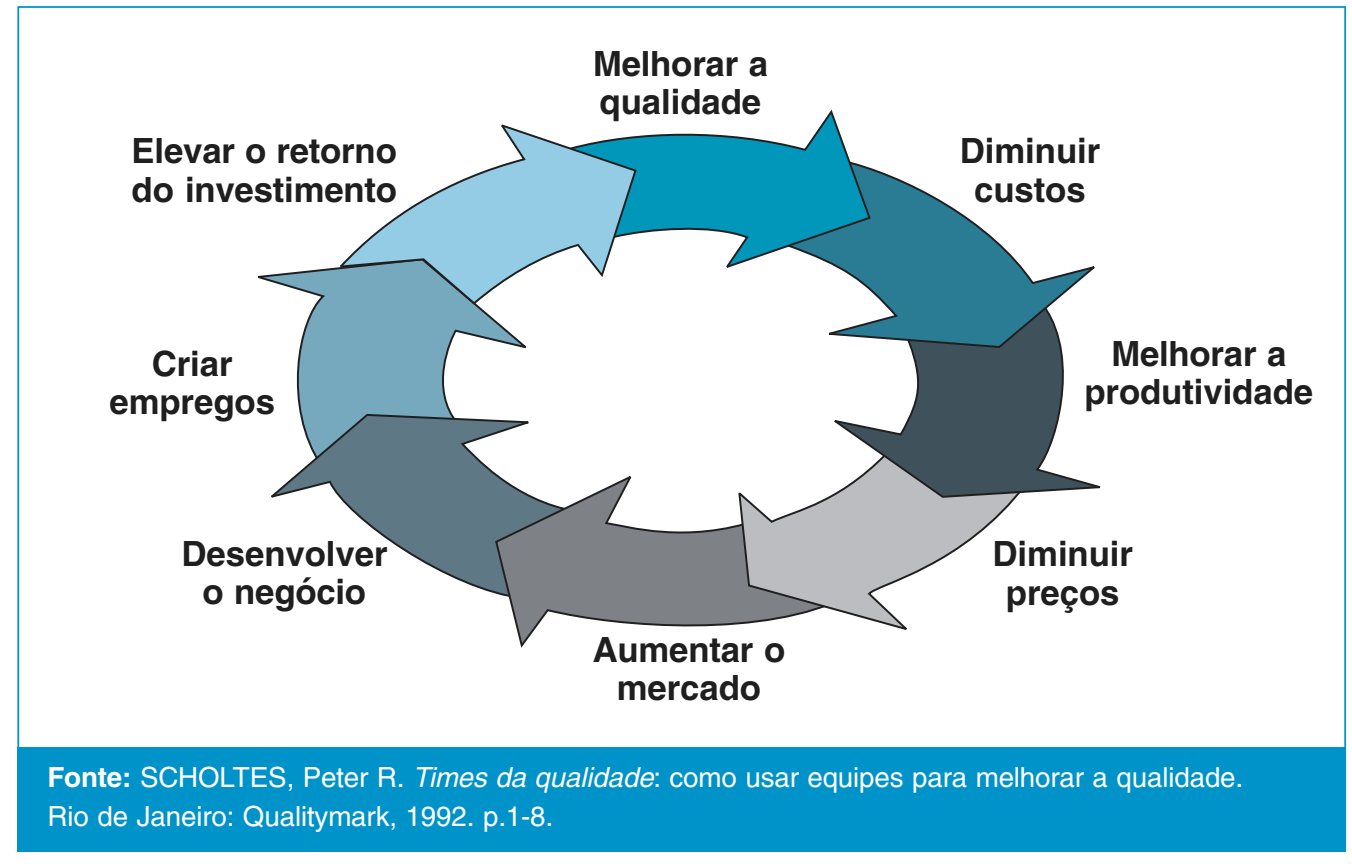


Figura 3 - Qualidade relativa eleva taxas de retorno

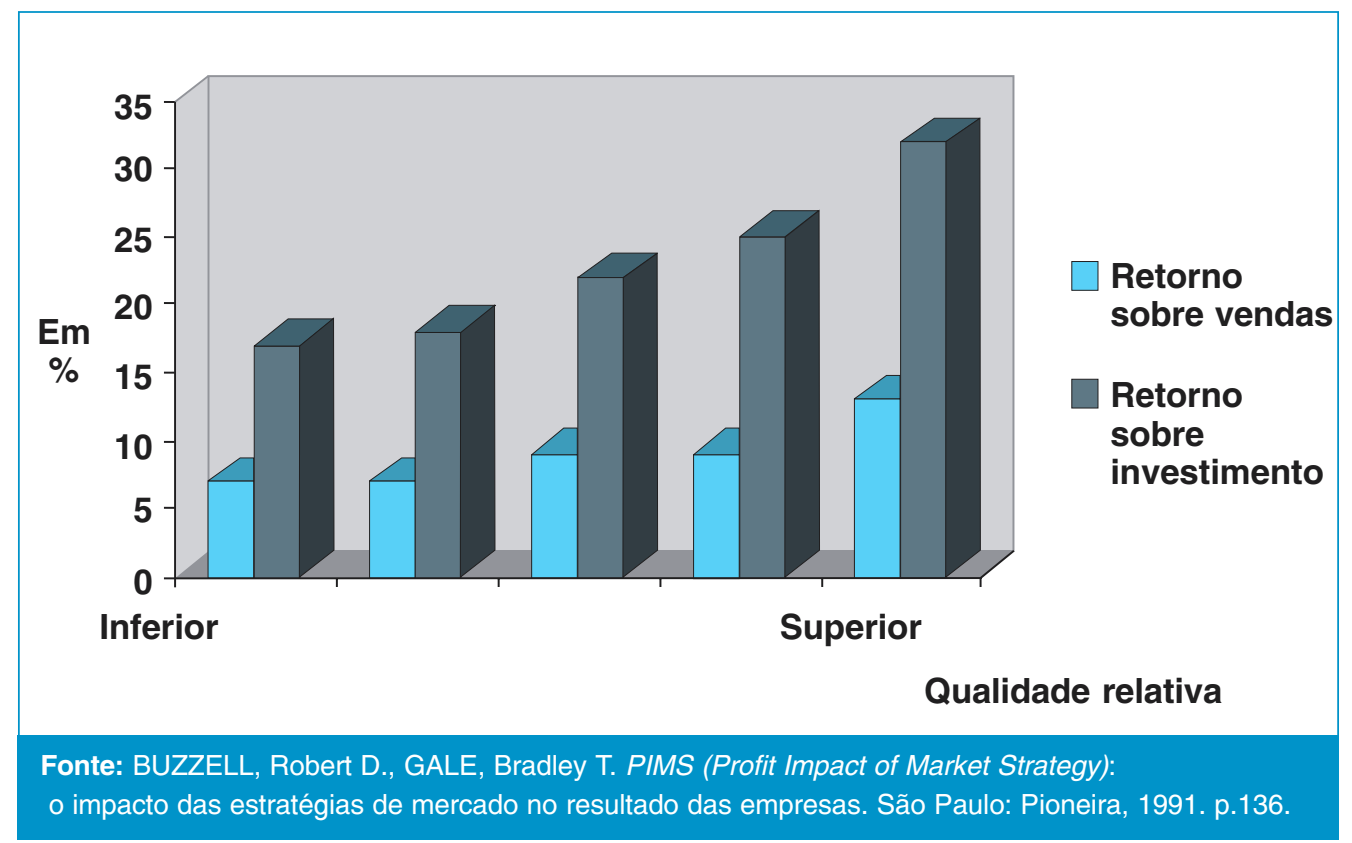

O sistema da administração para a qualidade total mostrado por Barrow ${ }^{9}$ reforça a importância da orientação para o atendimento das necessidades dos consumidores como diretriz para os esforços da empresa.
Em relação ao futuro, a perspectiva de Juran, ${ }^{10}$ ao afirmar que "o século 21 será o século da qualidade", nos estimula ainda mais a analisar o tema e sua utilidade para o desenvolvimento do segmento em foco: os supermercados. Como consideramos anteri-

Figura 4 - 0 sistema da administração para a qualidade total

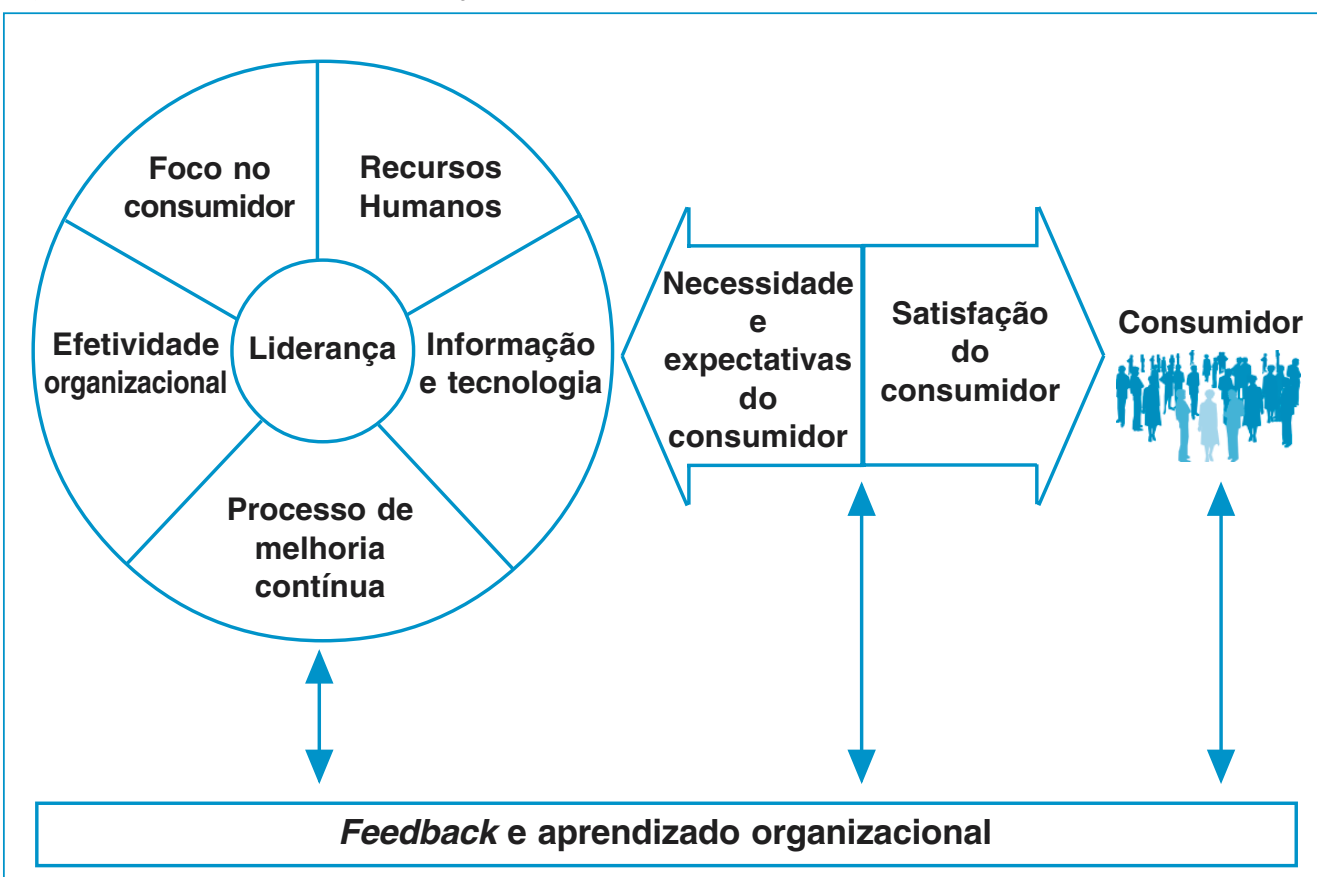

Fonte: Adaptado de BARROW, James W. Does total quality management equal organizational learning? Quality Progress, July 1993, p.39.
9. BARROW, James W. Does total quality management equal organizational learning? Quality Progress, July 1993, p.39.

10. JURAN, J. M. Made in USA: a renaissance in quality. Harvard Business Review, July-Aug.1993, p.47. 
11. KOTLER, Philip. Administração de marketing: análise, planejamento, implementação e controle. São Paulo: Atlas, 1995. p.57.

12. REICHHELD, Frederick \& SASSER Jr. W. Earl. Zero defections: quality comes to services. Harvard Business Review. Sep.Oct., 1990, p.105-11.

13. Whiteley, R. C. A empresa totalmente voltada para o cliente. Rio de Janeiro: Campus, 1992. p.19-33.

14. BERRY, L., PARASURAMAN, A. Serviços de marketing: competindo através da qualidade. São Paulo: Maltese, 1992. p.17-22 ormente, os supermercados no Brasil vêm passando por uma necessária busca de produtividade para obter resultados em um mercado mais competitivo e economicamente estável. Assim, queremos considerar que a melhoria de qualidade deva ser um caminho natural para o varejista na conquista da produtividade.

\section{O CONSUMIDOR ESTÁ MAIS EXIGENTE}

Conforme mostra Kotler, ${ }^{11}$ as empresas de hoje estão se esforçando mais para reter seus consumidores, o que é justificado pelo fato de que o custo de atrair novos consumidores pode chegar a ser cinco vezes o custo de manter um consumidor feliz. Reichheld \& Sasser ${ }^{12}$ ressaltam que uma empresa pode chegar a melhorar seus lucros entre $25 \%$ e $85 \%$ ao reduzir a taxa de abandono de seus consumidores em apenas $5 \%$.

Um fator verificado no mercado brasileiro e que faz com que os supermercados se preocupem ainda mais com a qualidade é o maior grau de exigência que vem sendo observado por parte do consumidor. Considera-se que, já a partir do estabelecimento do Código de Defesa do Consumidor no início dos anos 90, mudamos todos - o consumidor, que está mais exigente, e as empresas, que estão mais preocupadas e cientes da importância de atender bem.

\section{QUALIDADE EM PRODUTOS E SERVIÇOS}

Whiteley ${ }^{13}$ mostra que as poderosas técnicas introduzidas por Deming e Juran lidam, sobretudo, com a qualidade dos produtos, que costuma ser quantificável. Nas empresas como os supermercados, que vendem produtos e oferecem serviços, a qualidade consiste em aspectos tangíveis do produto, no entanto, a qualidade do serviço pode ser descrita como intangível, sendo mais difícil de medir do que a qualidade do produto. Whiteley apresenta o que denomina o quadro da qualidade com enfoque no cliente, que apresentamos na Figura 5.

Whiteley mostra que as empresas vitoriosas são aquelas que efetivamente oferecem qualidade em produtos e serviços. Esse enfoque nos parece bem adequado para a atividade supermercadista, em que os produtos oferecidos aos clientes recebem o enfoque da qualidade em produtos, ao mesmo tempo em que o atendimento é um serviço fundamental para a satisfação do cliente.

Berry \& Parasuraman ${ }^{14}$ também ressaltam a importância da orientação de esforços no atendimento ao consumidor para que a instituição alcance a excelência em serviços. Entre outros exemplos de orientação para a satisfação do consumidor, os autores mostram o esforço de um supermercadista na conquista da satisfação de seu cliente.

Figura 5 - Quadro da qualidade com enfoque no cliente

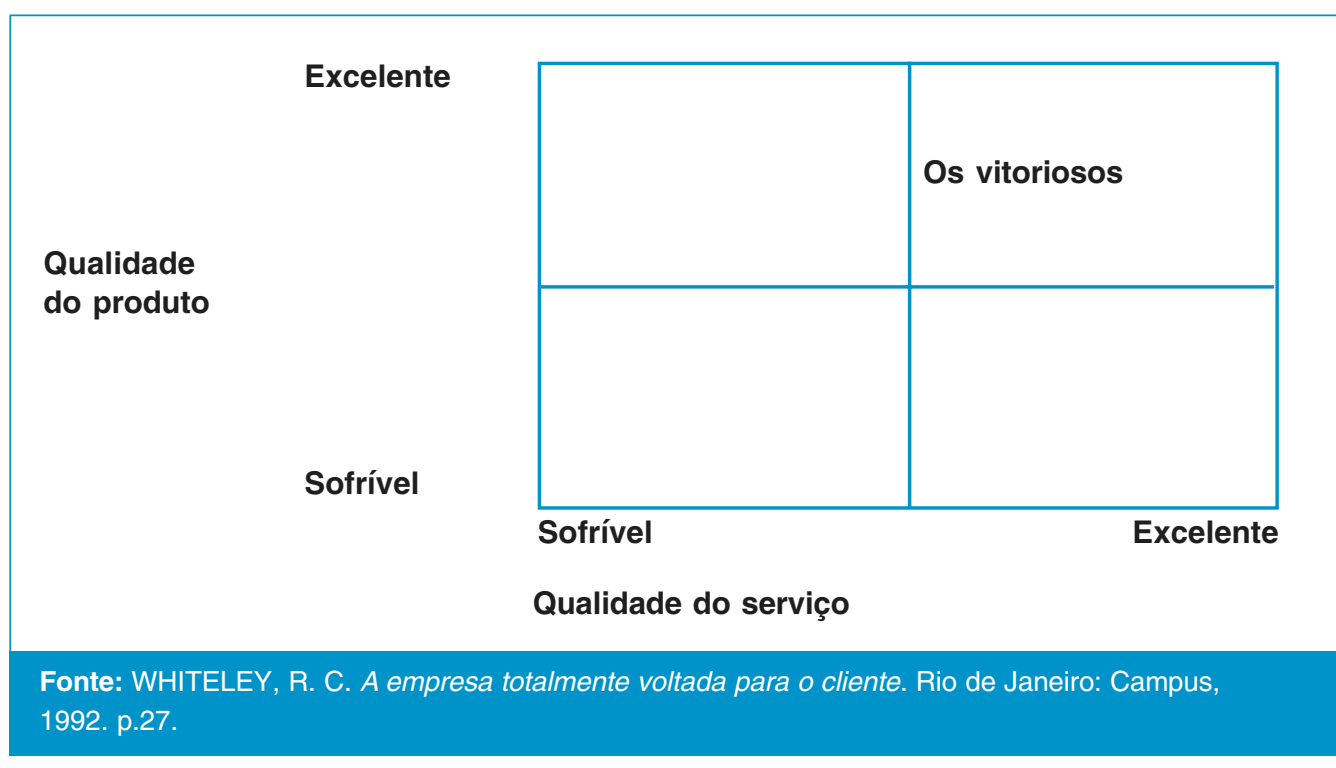


O exemplo refere-se a uma dona de casa que está comprando abacaxi em um supermercado, o Ukrop's Super Markets. Ela escolhe um enorme abacaxi na banca de frutas e reluta em comprá-lo. O presidente da empresa vê a cena e pergunta se ela gostaria de comprar metade do abacaxi, indicando com isso que o supermercado teria prazer em cortá-lo ao meio. A cliente aceita e afirma que gosta muito de ir ao Ukrop's porque a equipe é muito gentil e a faz sentir-se muito bem recebida.

O esforço e a atenção desse varejista com seu cliente naturalmente representam o reforço da confiança e credibilidade da loja, aumentando a fidelidade dessa dona de casa com o estabelecimento.

\section{QUALIDADE NOS} SUPERMERCADOS: O EXEMPLO DE STEW LEONARD

Antes de analisarmos qualquer resultado sobre tendências e indicadores de desempenho dos supermercados brasileiros, vamos adotar uma das recomendações de Whiteley, ${ }^{15}$ ou seja, vamos aprender com os vitoriosos. Um exemplo de sucesso que, durante os anos 90, vem sendo reconhecido no mundo inteiro e também entre os supermercadistas brasileiros é o dos Supermercados Stew Leonard's.

A Stew Leonard's tem duas lojas, a primeira em Norwalk, Connecticut, inaugurada em 1969, com 4 mil m² de área de vendas, a segunda em Dambury, com 6 mil $\mathrm{m}^{2}$, aberta em 1991. Trabalha com variedade pequena, cerca de 800 itens, sendo $90 \%$ alimentos. O ambiente criado é de excitação total, procurando levar o cliente a exclamar "Uau", diante de cada seção, de cada detalhe. Conquistou uma menção no Guiness em 1992 como a maior venda $/ \mathrm{m}^{2}$ dos Estados Unidos.

Reconhecido mundialmente por seu desempenho e orientação para a qualidade, os Supermercados Stew Leonard's mostram uma forte orientação para o atendimento às necessidades do consumidor e um exemplo da aplicação da filosofia de administração orientada para a busca da qualidade em supermercados.

Stew Leonard é citado por Kotler ${ }^{16}$ como uma ilustração clara do valor de duração do cliente. Stew Leonard vê US\$ 50 mil "voando" para fora de sua loja cada vez que per- cebe um cliente insatisfeito, calculando esse valor da seguinte forma:

- gasto médio por cliente = US\$100 semanais;

- compram em média 50 semanas por ano;

- moram na região por um período médio de 10 anos.

\section{As EMPRESAS VITORIOSAS SÃO AQUElAS QUE efeivameNIE ofereCEM QualidadE EM PROdUtos e SeRviços.}

Assim, se um cliente tem uma experiência infeliz na loja e troca de supermercado, Stew Leonard considera que perdeu US\$ 50 mil em faturamento. Isso sem contar o prejuízo causado por um consumidor insatisfeito que passa a falar mal da loja, influenciando outras pessoas.

As principais ações da empresa na constante busca pela excelência em suas lojas são descritas pelo próprio Stew Leonard em uma entrevista publicada na International Trends in Retailing e reproduzida pela ABRAS. ${ }^{17} \mathrm{Os}$ pontos-chave do trabalho realizado por Stew Leonard são:

\section{- Filosofia de trabalho: satisfação do cliente}

A diferença da Stew Leonard's está na filosofia de trabalho, expressa a todos já na entrada da loja, esculpida em uma grande pedra:

"Regra no 1: O consumidor tem sempre razão.

Regra $n^{\circ}$ 2: Se ele estiver errado, leia novamente a regra $n^{-} 1 . "$

Essa filosofia é praticada por todos os funcionários e levada às últimas conseqüências: eles fazem de tudo para que o cliente se sinta com a razão.
15. WHITELEY, R. C. Op. cit., p.19-33. 16. KOTLER, Philip. Op. cit., p.61.

17. ABRAS - Associação Brasileira de Supermercados. 0 objetivo é criar clientes felizes. Superhiper, São Paulo, maio 1992, p.157-72. 


\section{- Ambientação da loja}

Segundo Stew Leonard, os clientes querem um ambiente alegre, divertido, diferente da chatice que é fazer compras. Assim, já antes de os clientes entrarem na loja, se encantam com um verdadeiro zoológico - galinhas, marrecos, vacas e ovelhas -, que conquista a simpatia de crianças e adultos. $\mathrm{O}$ clima country é expresso na decoração, toda em madeira.

\section{Qualidade,} ATENdIMENIO E PREÇO FORMAM UM IRIPÉ, SEM QUE UM EXCluA $O$ OUTRO.

- Envolvimento e participação da equipe

Uma das características importantes da empresa é o treinamento, a participação e a motivação dos funcionários, procurando fazer com que as pessoas se sintam envolvidas. O treinamento é muito importante para a empresa, tanto é que foi criada a Universidade Stew Leonard. Um dos ensinamentos aos funcionários é que "se você estiver treinando alguém para ser melhor do que você na sua tarefa, você é uma das pessoas mais valiosas da nossa empresa... e uma das mais propensas a serem promovidas".

\section{- Pesquisas para ouvir os clientes}

Segundo Stew Leonard, "o cliente que reclama é o seu melhor amigo, se ouvirmos essas pessoas, podemos melhorar sempre". Além da postura constante de dar atenção e ouvir os clientes, Stew Leonard adota duas técnicas de pesquisa para obter informações:

a) Comitê de clientes: Uma vez por mês é realizada uma discussão em grupo com cerca de 15 clientes em cada loja. Os dirigentes da empresa sentam-se em uma sala e fazem uma "viagem de compras" imaginária, perguntando aos clientes do que eles gostam e não gostam nas lojas.

b) Urna de sugestões: Conforme o próprio Stew Leonard, a sabedoria popular diz que as urnas de sugestões vivem vazias. Mas isso não ocorre em suas lojas, em que as urnas estão sempre cheias, e a razão para isso é a reação da empresa em relação às sugestões dos clientes. Diariamente recebem cerca de 100 sugestões ou comentários sobre a loja. Todas as manhãs as sugestões são recolhidas e são elaborados relatórios datilografados, que circulam entre os gerentes das seções até às 11 horas do mesmo dia. Cada gerente deve reagir o mais rápido possível para atender às sugestões dos clientes.

\section{- Projetos de melhoria em função da opi- nião dos clientes}

As sugestões dos clientes são analisadas e implantadas por meio de projetos de implantação visando a melhorias constantes.

\section{- Relacionamento com fornecedores}

A Stew Leonard's procura estabelecer um entrosamento tão bom com os fornecedores como com seus clientes e funcionários. Tem um prêmio para fornecedores que se destacam e faz questão de visitá-los regularmente para fortalecer o relacionamento. Considera que, se tiver um bom relacionamento com os fornecedores, gostando deles, terá como retorno empresas que também irão reconhecer o seu trabalho e fazer o máximo para oferecer os melhores produtos pelos melhores preços.

\section{- O que os clientes devem esperar em uma loja}

Segundo Stew Leonard, o cliente precisa encontrar produtos melhores e mais frescos do que esperava, funcionários corteses, rápidos no atendimento, e tudo por um preço melhor. Assim é possível criar entusiasmo nos clientes. Qualidade, atendimento e preço formam um tripé, sem que um exclua o outro.

\section{COMO OS SUPERMERCADISTAS BRASILEIROS PERCEBEM O FATOR QUALIDADE}

Pela convivência com o setor, workshops realizados com supermercadistas, debates sobre o assunto e contatos informais feitos com 
profissionais da área nos últimos anos, é possível perceber que existe uma orientação crescente para o atendimento ao consumidor e para a melhoria de qualidade como forma de diferenciação e até sobrevivência das lojas.

Procurando fundamentar melhor essa percepção, foi realizado um levantamento das principais publicações do setor dos últimos 20 anos e entrevistas em profundidade com 15 dirigentes de redes de supermercados na Grande São Paulo, procurando representar redes de grande e médio portes.

\section{As pesquisas e a orientação para o consumidor}

Vários fatores reforçam a percepção de que, durante os anos 90, o setor supermercadista passou a investir maiores esforços na melhoria do atendimento e de serviços aos consumidores. Holovko, ${ }^{18}$ Diretor de Recursos Humanos do Sé Supermercados, ressalta que várias experiências em diferentes estados do Brasil já vêm sendo realizadas com a implantação de um comitê de clientes.

Entre os supermercadistas entrevistados na Grande São Paulo, pudemos perceber que ouvir o consumidor é uma ação considerada muito importante para identificar caminhos de diferenciação da loja. Entre 15 entrevistados, 14 consideram que ouvir o consumidor é muito importante para orientar decisões de melhoria em suas redes de supermercados.
Pesquisas com consumidores são realizadas por 13 dos supermercados entrevistados. Almeida ${ }^{19}$ reforça essa constatação mostrando exemplos de vários supermercados brasileiros que estão efetivamente iniciando um esforço para atender o consumidor de forma diferenciada. Apesar da constatação da importância dada à implantação de pesquisas para ouvir os consumidores, a nossa percepção, através dos contatos com os dirigentes de supermercados, reforçada por Litvac, ${ }^{20}$ é a de que poucas redes desenvolveram mecanismos de pesquisa sistemáticos e com rigor metodológico para conhecer os desejos e anseios dos seus clientes. Parece haver um longo caminho ainda a ser percorrido.

\section{Os investimentos em informatização}

Para os supermercadistas, a informatização é considerada uma forma de melhorar a qualidade do seu processo de trabalho, gerando condições para maior eficiência, produtividade e conseqüente melhoria para o consumidor. A Figura 6 mostra o crescimento da presença da informática no setor supermercadista.

Os dados mostram a crescente adoção da informatização entre os supermercados, particularmente entre as lojas maiores, conforme mostra a Figura 7.

Entre as 20 maiores redes de supermercados, todas têm lojas informatizadas. Já entre as 300 maiores, o percentual de empresas informatizadas é menor, mas cresceu entre os anos de 1995 e 1996, atingindo $75 \%$ do total.

Figura 6 - Número de supermercados informatizados no Brasil

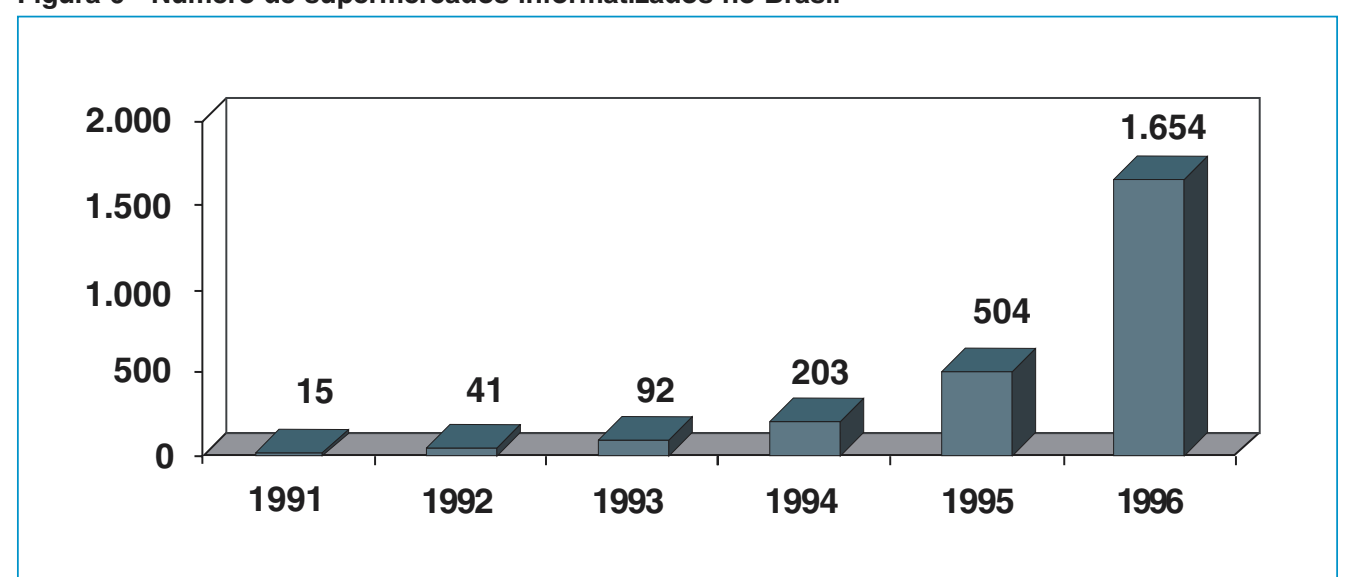

Fonte: NIELSEN, A. C. Estrutura do varejo brasileiro. São Paulo, 1997. p.123.
18. HOLOVKO,Igor B. Comitê de clientes: uma idéia para recuperar a comunicação perdida. Superhiper, out. 1993, p.158.

19. ALMEIDA, Luiz G. Surpreenda, empolgue, segure 0 seu cliente. Superhiper, mar. 1993, p.81-94.

20. LITVAC, S. Por que meu concorrente ganha terreno? Superhiper, dez. 1995, p.146-52. 
Figura 7 - Percentual de empresas com lojas informatizadas

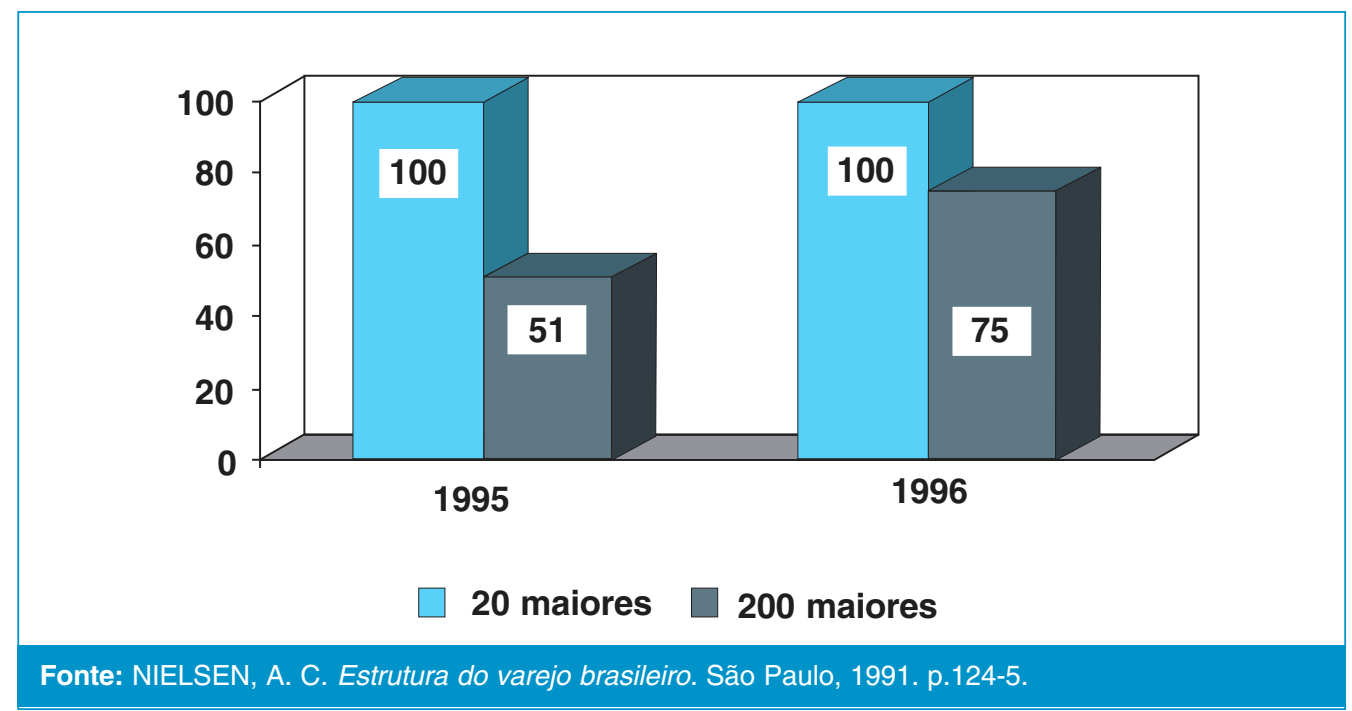

Figura 8 - Investimento médio por check out (em milhares de dólares)

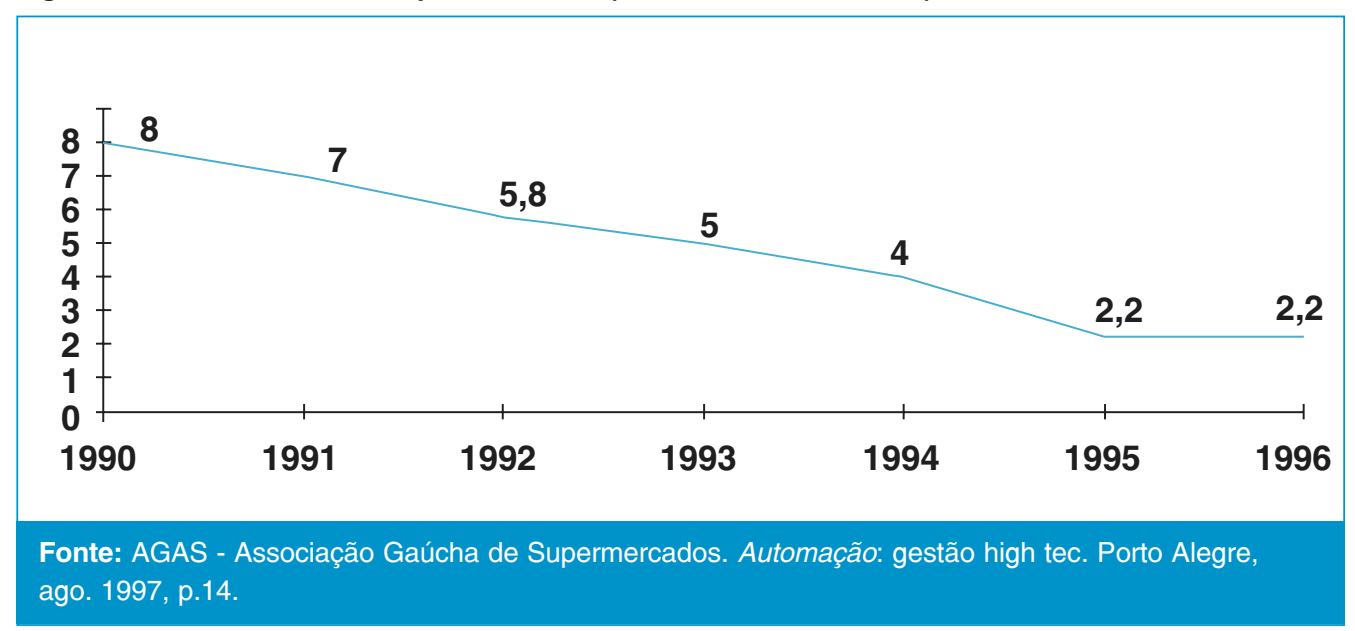

Figura 9 - Grau de satisfação dos funcionários de supermercados com sua profissão (em \%)

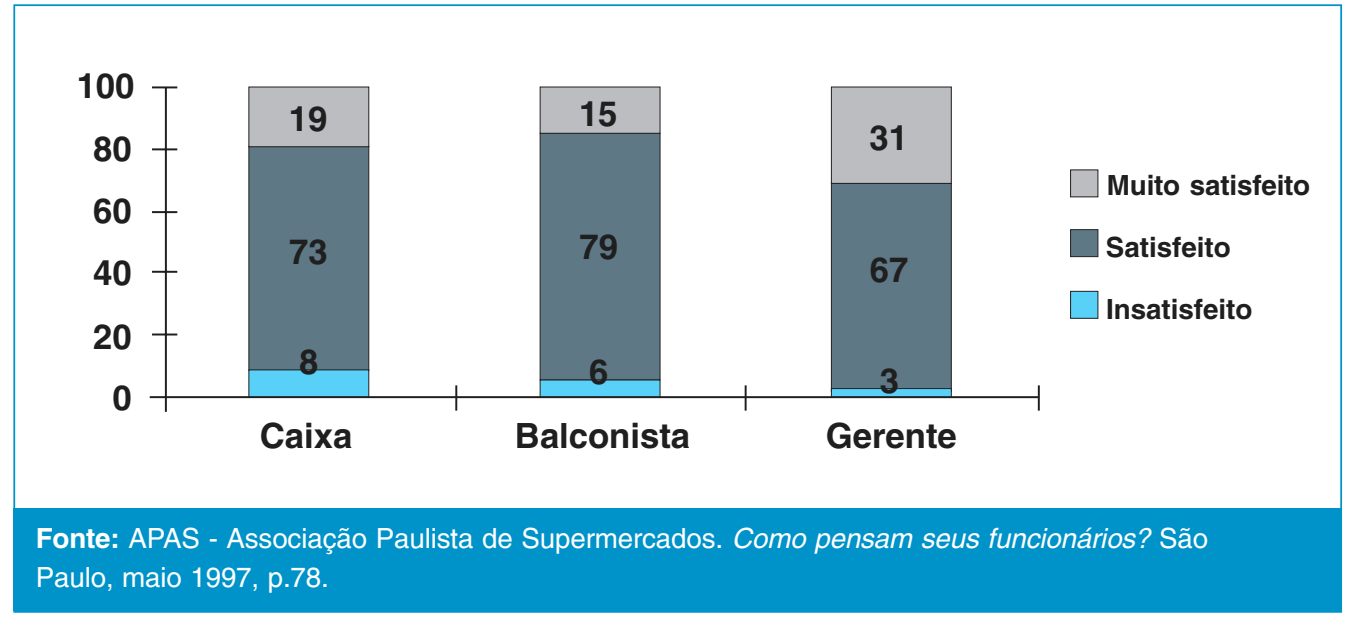


Um dos motivos que viabilizaram a aceleração da informatização nos supermercados foi a redução do investimento médio para informatização por check out (caixas registradoras na saída da loja), como mostra a Figura 8.

Segundo os supermercadistas entrevistados, a informatização é um fator de melhoria na qualidade de atendimento aos consumidores, particularmente na frente de caixa, e também importante ferramenta para disponibilizar dados de forma mais ágil e precisa, permitindo decisões com base em melhores informações. A informatização é considerada um meio para efetiva melhoria nos padrões de qualidade dos supermercados brasileiros.

\section{Investimento nos funcionários}

Durante os anos 90, exemplos foram sendo constituídos por supermercados que apresentaram esforços na melhoria das relações com seus funcionários. Entrevistas com dirigentes de alguns supermercados mostram a preocupação crescente em valorizar seus funcionários, ouvir o que eles têm a dizer e vê-los como aliados. Segundo esses dirigentes, uma grande verdade se esconde atrás de uma idéia simples e óbvia: só um funcionário satisfeito pode transmitir satisfação aos clientes, sem os quais não se salvam nem o patrão nem o empregado. Nas empresas entrevistadas estão sendo realizadas ações como:

- criação de grupos e associações de funcionários da empresa;

- pesquisas para identificar necessidades e prioridades de melhoria;

- estabelecimento de política de incentivos;

- treinamento e desenvolvimento gerencial;

- incentivo à carreira;

- programas de benefícios;

- trabalho em equipe.

Pesquisa realizada pela Indicator e Associação Paulista de Supermercados, publicada em APAS, ${ }^{21}$ com 270 entrevistas em São Paulo e no interior do Estado, mostra que o perfil dos funcionários que mais estão em contato com os clientes, como operadores de caixa e balconistas, é predominantemente de classes $\mathrm{C}$ e $\mathrm{D}$, a maio- ria com educação em nível ginasial. Entre os entrevistados a maior parte mostra-se satisfeita com a profissão, como vemos na Figura 9.

Apesar de a maior parte dos entrevistados já ter recebido algum tipo de treinamento, os dados seguintes indicam que ainda há muito a ser feito, já que $35 \%$ dos entrevistados nunca receberam cursos ou treinamento, conforme mostra a Figura 10.

Entre os cursos realizados, a maior parte diz respeito ao atendimento a clientes, indicando uma preocupação do supermercadista com esse tema.

\section{Os conceitos de qualidade total nos supermercados brasileiros}

No início dos anos 90, os conceitos de qualidade total ainda eram considerados relativamente pouco difundidos no comércio, mas percebia-se um interesse crescente do setor, conforme mostra Lapenna. ${ }^{22} \mathrm{E}$ é nas empresas de serviços e comércio que os métodos de qualidade total podem trazer resultados mais evidentes justamente pela relação direta entre a gestão dos recursos humanos, a produção do serviço e a convivência com o consumidor.

Segundo O'Connor, ${ }^{23}$ os supermercadistas têm muito a aprender com os processos vividos pelos japoneses para a melhoria da qualidade, o que, no entanto, é um esforço de longo prazo, exigindo envolvimento da alta direção. $\mathrm{O}$ assunto passou a se disseminar de forma crescente entre as empresas,

\section{Figura 10 - Treinamento para funcionários de} supermercados

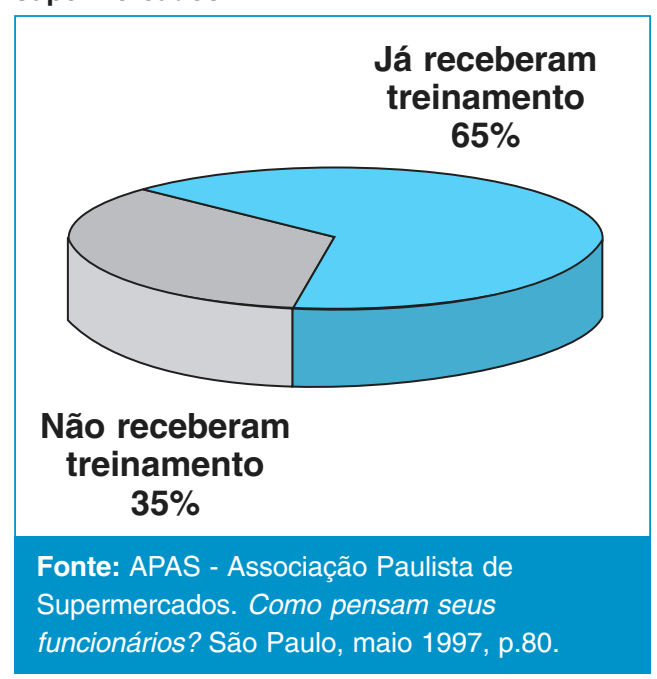

21. APAS - Associação Paulista de Supermercados. Como pensam seus funcionários? São Paulo, maio 1997, p.74-83.

22. LAPENNA, Luca. 0 que pensa 0 comércio sobre a qualidade total. Superhiper, maio 1992, p.176.

23. O'CONNOR, M. O varejo enxuto. Superhiper, mar. 1992, p.33-46. 
despertando cada vez mais a necessidade de implantação de ações efetivas, conforme reforça Zulzke. ${ }^{24}$

Entre os 15 supermercadistas entrevistados na Grande São Paulo, a maioria (12 entrevistados) considera muito importante a implantação de programas de qualidade total como elemento de melhoria e diferencial competitivo para o supermercado. Uma pesquisa realizada pelo Sebrae Nacional e publicada por Sobral ${ }^{25}$ também mostra o interesse de micro e pequenas empresas varejistas pela melhoria de qualidade, conforme demonstrado na Figura 11.

\section{CONCLUSÕES}

A evolução dos supermercados nas últimas décadas tem estado associada à maior competitividade e necessidade de maior eficiência do setor. A partir do Plano Real, com a estabilização econômica, verifica-se um acirramento da concorrência e a necessidade de orientar esforços mais efetivos para atender um consumidor cada vez mais exigente.

Os conceitos de qualidade total, visando à busca de excelência no atendimento ao consumidor, estão associados à diminuição de custos de operação decorrentes de maior

Figura 11 - Temas de maior interesse em micro e pequenas empresas varejistas (em \%)

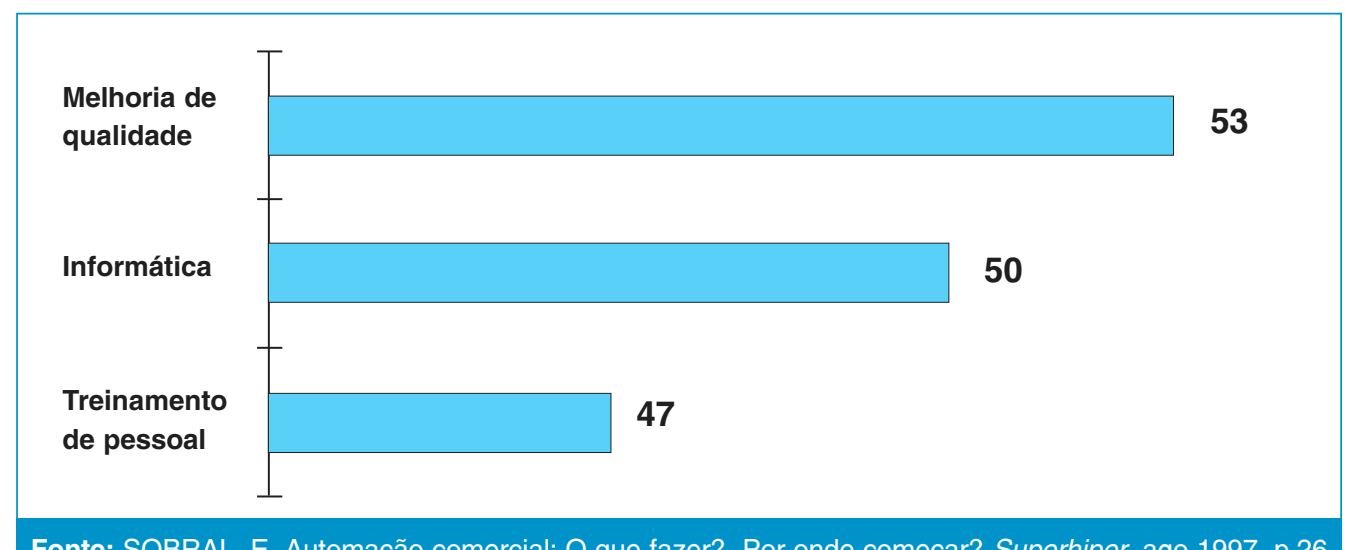

No entanto, segundo os próprios dirigentes de supermercados, ainda há muito a ser feito. Essa percepção é reforçada pelas entrevistas realizadas, em que verificamos que a maior parte dos supermercadistas têm ações implantadas em busca da qualidade total, mas 5 entre 15 entrevistados ainda não desenvolvem esforços nesse sentido. Segundo os supermercadistas que já estão desenvolvendo esforços em busca da melhoria de qualidade, é fundamental que a loja ofereça instalações modernas e adequadas ao seu público consumidor, funcionários bem treinados e preparados para um bom atendimento, qualidade nos produtos que oferecem, redução de desperdícios através de controle de perecíveis e muito empenho para criar alternativas que satisfaçam os consumidores, diferenciando-se da concorrência. Consideram que é um processo contínuo, sem fim, sendo que a cada instante devem ser buscadas novas soluções para melhoria na gestão das lojas. produtividade e eficiência no processo de trabalho. Estudos mostram também que a melhoria de qualidade está associada a maiores taxas de retorno sobre o investimento.

Diante de um consumidor mais exigente, torna-se ainda mais importante buscar a qualidade em produtos e serviços. Procurando aprender com um exemplo de excelência em supermercados, destacamos Stew Leonard, reconhecido mundialmente pelo trabalho de qualidade orientado para o atendimento de seus consumidores.

Entre os supermercadistas brasileiros, verificam-se um maior esforço no conhecimento de seus consumidores, investimentos em informatização e em funcionários e uma crescente preocupação com a qualidade. A qualidade passa a ser percebida não só como uma questão de aprimoramento do negócio, mas como uma necessidade fundamental para a sobrevivência e o desenvolvimento do supermercado em uma nova era cada vez mais competitiva.
25. SOBRAL, E. Automação comercial: 0 que fazer? Por onde começar? Superhiper, ago. 1997, p.20-30. 